\title{
Fragmentation: Is the Message Clear?
}

\author{
$\underline{\text { John A. Bissonette }}^{1}$ and $\underline{\text { Ilse Storch }}^{2}$
}

\begin{abstract}
In this paper, we briefly discuss some of the fundamental problems arising from the inherent complexity of larger-scale ecological systems. We examine the tenuous assumption of a direct correspondence between ecological data and theory, we comment on a recent report that evaluated the efficacy of fragmentation experiments, and we briefly assess its implications for ecological research and conservation practice on the landscape scale.
\end{abstract}

\section{INTRODUCTION}

Linking theory and data is not an easy task, especially at larger spatial extents and temporal horizons. For this reason, capturing ecological reality has been a more difficult task than landscape ecologists previously may have appreciated. In addition, translating fragmentation effects into terms that can be understood and used in management has been most difficult (Villard 2002). The trouble is that ecological complexity at all scales tends to blur research results, with patterns that are more often than not equivocal, especially when results from several studies are compared (Debinski and Holt 2000, McGarigal and Cushman 2002). Consequently, the researcher is left to interpret "noisy" study results in the light of what are assumed to be realistic theoretical and conceptual frameworks. Indeed, the noise or variation may inform the theory.

The origins of our trust in ecological theory and concepts may spring from advances in knowledge gained from the mostly successful attempts of mechanistic and experimental science to discover "answers" to smaller-scale ecological questions. However, all answers are circumscribed by what O'Neill et al. (1985) have termed our "observation set." The questions we ask, the variables we measure, and the analyses we use always constrain the domain of possible answers. Additionally, ecologists have tended to ask "solvable" questions. Messy, intractable problems have not been addressed until advances in technology or paradigmatic theory made them more tractable. For example, the development of landscape metrics software, the ability to gather and analyze digital landscape data, and the realization that scale matters have allowed ecologists to ask questions regarding the effects of landscape fragmentation that could not have been addressed earlier. However, even the most sophisticated technological tools are just tools, and new paradigms are always more complex than their initial use would indicate.

Given these tendencies, it is easy for ecologists to be insufficiently introspective when interpreting their results. In ecology, experimentation has long been regarded as the most rigorous of scientific approaches (Platt 1964). Thus, we might expect a "rigorous experimental approach" to provide more insight into the effects of larger-scale habitat fragmentation than do the more traditional observational, historical, and comparative approaches. However, do the data support this contention? Debinski and Holt's (2000) recent survey of habitat fragmentation experiments provides a troublesome message and suggests that the answer to this question is: "not necessarily."

\section{FRAGMENTATION EXPERIMENTS: IS THE MESSAGE CLEAR?}

In their enlightening review of habitat fragmentation experiments, Debinski and Holt (2000) not only provide an excellent analysis of the few studies that have actually used experiments to refute or support a priori hypotheses about fragmentation effects, but their results also speak volumes about the complexity of the causal mechanisms attendant to habitat change. Debinski and Holt (2000) report the results of 20 studies (21 if a notational account given in the acknowledgements is included) that tested six major groups of hypotheses. These hypotheses concern: (1) the relationship of species richness to area, (2) the relationship of species abundance or density to area,

\footnotetext{
${ }^{1}$ Utah Cooperative Fish and Wildlife Research Unit, U.S. Geological Survey; ${ }^{2}$ Wildlife Research and Management Unit, Technical University of Munich and Max Planck Research Centre
} 
(3) whether interspecific interactions are modified by fragmentation, (4) whether edge effects influence ecosystem "services," (5) the relationship between corridors and movement between habitat fragments, and (6) whether connectivity increases species richness. The results are interesting and informative. Only six of 14 (37.5\%) studies supported the expectations of the first and sixth hypotheses, i.e., that species richness would increase with increasing area or connectivity. The expectation for the second hypothesis is that the abundance and density of specialist species should decrease with increasing fragmentation, although movement dynamics between different habitat elements (matrix vs. patch) might result in increases. Debinski and Holt (2000) found that species abundance decreased with increasing fragmentation in only six of 13 studies (46.2\%). The prediction for the third hypothesis is that some modification is expected, and it was supported in the two studies that addressed the question; both of them involved arthropod populations. An expectation from theory is that an increase in edge relative to core areas (the fourth hypothesis) can have profound effects on ecological processes (Saunders et al 1991, Debinski and Holt 2000). Two of three $(66.6 \%)$ studies supported the hypothesis on edge effects. The expectation for the fifth hypothesis is that fragmentation inhibits movement and prevents the formation of corridors, with the result that connectivity should be positively correlated with increased movement. Debinski and Holt (2000) found that four of five $(80 \%)$ of the studies they evaluated supported this hypothesis, at least for some species. They found mixed results for predictions involving species richness (e.g., Laurance and Bierregaard 1996, Collinge 1995 vs. Schmiegelow et al. 1997, Margules 1996), density and abundance of species (e.g., Foster and Gaines 1991, Margules and Milkovits 1994 vs. Barrett et al. 1995, Collins and Barrett 1997), edge effects (e.g., Bierregaard et al. 1992, Klenner and Huggard 1997 vs. Robinson et al. 1992), and corridors and movements (e.g., Haddad 1997, Wolff et al. 1997 vs. Andreassen et al. 1988). The results were "entirely mixed." Debinski and Holt (2000) credit time lags, scale inconsistencies, contingent social interactions between species, and habitat generalists as some of the reasons for these mixed results.

Although this certainly suggests that there are serious problems with experimental approaches, comparative mensurative studies (the more traditional observational, historical, and comparative approaches) appear to perform no better. McGarigal and Cushman
(2002) reviewed 134 fragmentation studies, 43\% of which were observational. They found that, regardless of whether they were manipulative (experimental) or mensurative, fragmentation studies did not provide clear insights into system dynamics.

The hypotheses examined are of fundamental interest to ecologists who strive to understand the underlying conceptual framework governing fragmentation effects, and to managers charged with carrying out "ecosystem management" (Walters 1986, Walters and Holling 1990, Forest Ecosystem Management Assessment Team 1993, Grumbine 1994, 1997), or with conserving biodiversity (Noss et al. 1994, 1995). The clear message appears to be that straightforward predictions do not capture the multicausal nature of organism response to fragmentation. For example, generalist species can be expected to respond differently than specialists. Similarly, early successional species, transient organisms (usually younger individuals), and edge- and core-sensitive species can be expected to respond differently to landscape fragmentation (Bissonette et al. 1997, Debinski and Holt 2000, Storch 2002). Time lags will be common and have profound effects. Additionally, matching time and spatial domains remains a problem.

Delcourt et al. (1983), Wiens (1989), Holling (1992), and Bissonette (1997) have all suggested that there is an approximate matching between spatial and temporal scales in ecological processes. For example, the global distribution of forested landscapes changes at a speed of tens of thousands of years; regionally, forest disturbances such as fire occur at intervals from a few to hundreds of years; and, locally, vegetation changes within annual cycles. What this means is that time lags can be expected to occur in landscape-scale interactions. The decline of sugar maple (Acer saccharum) forests in the northeastern United States over the past half century or more is an excellent example of this, because not only is the extent of the damage more difficult to quantify, but its cause is also exceedingly difficult to determine because of the time lags involved. Additionally, the pattern of decline extends over hundreds of miles, but appears to be caused by local effects of soil acidification. Air-borne pollutants from the midwestern United States are carried by the prevailing west-to-east weather pattern, and acidified pollutants are deposited in the eastern United States. Several hypotheses have been suggested for the large-scale decline of sugar maple trees. Insect defoliation, drought, and historic land-use practices have been proposed as causal (Driscoll et al. 2001), 
but have not been supported (Swistock et al. 1999, Drohan 2000, Horsley et al. 2000). Rather, Sharpe and Sunderland (1995) and Sharpe et al. (1999) argue persuasively that acid deposition on forest soils, coupled with very long lag times in soil response, accounts for the sugar maple decline. The mechanism appears to be soil acidification and is apparently referenced by critically low calcium:aluminum and calcium:magnesium ratios (Sharpe et al. 1999, Swistock et al. 1999). Time lags of many years and perhaps even decades appear to be operating, suggesting that critical thresholds of soil acidity need to be reached before the effects become apparent. Although this is only one example, time lags and threshold effects may be more prevalent than we have supposed. Much longer multiscale studies are needed to understand the putative causes. Time lags also involve major ramifications for management. Land management or species conservation measures that are likely to take years to show the desired effects are difficult to defend and are not popular with decision makers, who work with annual budgets and may be elected for short periods of time. Additionally, the public and media appear to respond much more readily to more concrete and immediate results that appear to have a connection with causality closer to $1: 1$.

\section{FINAL COMMENTS}

In their study, Debinski and Holt (2000) have done landscape ecologists a remarkable service. Their results tell us something very important about the effects of fragmentation. The essence of the message is that the effects of fragmentation can be understood as multicausal, exhibiting thresholds where they are unexpected; are characterized by time lags that may be unpredictable; are heavily influenced by the structural differences between the matrix and the patches, especially if the patches are disturbance rather than remnant patches; and are heavily dependent on the temporal and spatial scales of observation. In addition, their dynamics are contingent on system history and therefore subject to unpredictable stochastic events. What we have just described is a complex adaptive system (Levin 1999) that may be characterized by deterministic chaotic events (Peak 1997). Weather pattern dynamics may be an excellent example of this kind of system. The question then becomes: do we think that we, as landscape-oriented animal ecologists, can beat the weatherman when it comes to predictions? Weather forecasts are notoriously poor once they exceed time frames of more than a few days, despite the enormous amounts of data and sophisticated analytical tools that meteorologists have at their disposal. Sensitivity to initial conditions, i.e., system history, has an enormous effect. So what makes us believe that we should be able to do much better? Perhaps the message is that, at some general level of explanation, ecologists may have predictive power regarding the effects of fragmentation, but complexity is likely to make prediction of specifics difficult or impossible.

Responses to this article can be read online at: http://www.consecol.org/vol6/iss2/art14/responses/index.html

\section{Acknowledgments:}

Adapted from the authors' concluding chapter of Landscape Ecology and Resource Management: Linking Theory with Practice. Soon to be published by Island Press, Washington, D.C., and Covelo, California. Appearing here by permission of the publisher. We also thank R. D. Holt and T. Elmqvist for their thoughtful and constructive comments on the manuscript.

\section{LITERATURE CITED}

Andreassen, H. P., K. Hertzberg, and R. A. Ims. 1998. Space-use response to habitat fragmentation and connectivity in the root vole Microtus oeconomus. Ecology 79:1223-1235.

Barrett, G., J. D. Peles, and S. J. Harper. 1995. Reflection on the use of experimental landscapes in mammalian ecology. Pages 157-174 in W. Lidicker, editor. Landscape approaches in mammalian ecology and conservation. University of Minnesota Press, Minneapolis, Minnesota, USA.

Bierregaard, R. O., Jr., T. E. Lovejoy, V. Kapos, A. A. dos Santos, and R. W. Hutchings. 1992. The biological dynamics of tropical rainforest fragments: a prospective comparison of fragments and continuous forest. Bioscience 42:859-866.

Bissonette, J. A. 1997. Scale-sensitive ecological properties: historical context, current meaning. Pages 3-15 in J. A. Bissonette, editor. Wildlife and landscape ecology: effects of pattern and scale. Springer-Verlag, New York, New York, USA.

Bissonette, J. A., D. J. Harrison, C. D. Hargis, and T. G. Chapin. 1997. Scale-sensitive properties influence marten demographics. Page 368-385 in J. A. Bissonette, editor. Wildlife and landscape ecology: effects of pattern and scale. 
Springer-Verlag, New York, New York, USA.

Collinge, S. K. 1995. Spatial arrangement of patches and corridors in the landscape: consequences for biological diversity and implications for landscape architecture. Dissertation, Harvard University, Cambridge, Massachusetts, USA.

Collins, R. J., and G. W. Barrett. 1997. Effects of habitat fragmentation on meadow vole (Microtus pennsylvanicus) population dynamics in experimental landscape patches. Landscape Ecology 12:63-76.

Debinski, D. M., and R. D. Holt. 2000. A survey and overview of habitat fragmentation experiments. Conservation Biology 14:342-355.

Delcourt, H. R., P. A. Delcourt, and T. Webb III. 1983. Dynamic plant ecology: the spectrum of vegetation change in time and space. Quaternary Science Reviews 1:153-175.

Drohan, P. J. 2000. A study of sugar maple (Acer saccharum Marsh) decline during 1979-1989 in northern Pennsylvania. Dissertation, Pennsylvania State University, University Park, Pennsylvania, USA.

Driscoll, C. T., G. B. Lawrence, A. J. Bulger, T. J. Butler, C. S. Cronon, G. Eagar, K. F. Lambert, G. E. Likens, J. L. Stoddard, and K. C. Weathers. 2001. Acidic deposition in the northeastern United States: sources and inputs, ecosystem effects, and management strategies. Bioscience 51:180-198.

Forest Ecosystem Management Assessment Team. 1993. Forest ecosystem management: an ecological, economic, and social assessment. U. S. Government Printing Office, Washington, D.C., USA.

Foster, J., and M. S. Gaines. 1991. The effects of a successional habitat mosaic on a small mammal community. Ecology 72:1358-1373.

Grumbine, R. E. 1994. What is ecosystem management? Conservation Biology 8:27-38.

Grumbine, R. E. 1997. Reflections on "What is ecosystem management?" Conservation Biology 11:41-47.

Haddad, N. M. 1997. Do corridors influence butterfly dispersal and density? A landscape experiment. Dissertation, University of Georgia, Athens, Georgia, USA.

Holling, C. S. 1992. Cross-scale morphology, geometry, and dynamics of ecosystems. Ecological Monographs 62:447-502.

Horsley, S. B., R. P. Long, S. W. Bailey, R. A. Hallett, and T. J. Hall. 2000. Factors associated with the decline disease of sugar maple on the Allegheny Plateau. Canadian Journal of Forest Research 30:1365-1378.

Klenner, W., and D. Huggard. 1997. Faunal biodiversity studies at Sicamous Creek: background and rationale for the choice of species indicator groups. Pages 187-194 in C. Hollstedt and A. Vyse, editors. Sicamous Creek Silvicultural Systems Project: workshop proceedings. British Columbia Ministry of Forests Research Publication Number 24/1997, Victoria, British Columbia, Canada.

Laurance, W. F., and R. O. Bierregaard. 1996. Fragmented tropical forests. Bulletin of the Ecological Society of America 77:34-36.

Levin, S. A. 1999. Fragile dominion: complexity and the commons. Helix Books, Perseus Publishing, Cambridge, Massachusetts, USA.

Margules C. R. 1996. Experimental fragmentation. Pages 128-137 in J. Settele, C. R. Margules, P. Poschlod, and K. Henle, editors. Species survival in fragmented landscapes. Kluwer Academic, Dordrecht, The Netherlands.

Margules, C. R., and G. A. Milkovits. 1994. Contrasting effects of habitat fragmentation on the scorpion Cercophonius squama and an amphipod. Ecology 75:20332042.

McGarigal, K., and S. A. Cushman. 2002. Comparative evaluation of experimental approaches to the study of habitat fragmentation studies. Ecological Applications 12(2):335-345.

Noss, R. F., and A. Y. Cooperrider. 1994. Saving nature's legacy: protecting and restoring biodiversity. Island Press, Washington D.C., USA.

Noss, R. F., E. T. LaRoe, and J. M. Scott. 1995. Endangered ecosystems of the United States: a preliminary assessment of loss and degradation. U.S. Geological Survey, Washington D.C., USA.

O'Neill, R. V., D. L. DeAngelis, J. B. Waide, and T. F. H. Allen. 1985. A hierarchical concept of ecosystems. Monographs in Population Biology Number 23, Princeton University Press, Princeton, New Jersey, USA.

Peak, D. 1977. Taming chaos in the wild: a model-free technique for wildlife population control. Pages 70-100 in J. A. Bissonette, editor. Wildlife and landscape ecology: effects of pattern and scale. Springer-Verlag, New York, New York, USA.

Platt, J. R. 1964. Strong inference. Science 146:347-354.

Robinson, G. R., R. D. Holt, M. S. Gaines, S. P. Hamburg, M. L. Johnson, H. S. Fitch, and E. A. Martinko. 1992. Diverse and contrasting effects of habitat fragmentation. Science 257:524-526.

Saunders D. A., R. J. Hobbs, and C. R. Margules. 1991. Biological consequences of ecosystem fragmentation: a review. Conservation Biology 5:18-32.

Schmiegelow, F. K. A., C. S. Machtans, and S. J. 
Hannon. 1997. Are boreal birds resistant to forest fragmentation: an experimental study of short-term community responses. Ecology 78:1914-1932.

Sharpe, W. E., and T. L. Sunderland. 1995. Acid-base status of upper rooting zone in declining and nondeclining sugar maple (Acer saccharum Marsh) stands in Pennsylvania. Pages 172-178 in K. W. Gottschal and S. L. C. Fosbroke, editors. Proceedings of the Tenth Central Hardwood Forest Conference. U. S. Department of Agriculture, Forest Service General Technical Report NE197.

Sharpe, W. E., B. R. Swistock, and T. L. Sunderland. 1999. Soil acidification and sugar maple decline in northern Pennsylvania. Pages 191-197 in W. E. Sharpe and J. R. Drohan, editors. The effects of acid deposition on Pennsylvania's forests. Environmental Resources Research Institute, Pennsylvania State University, University Park, Pennsylvania, USA.

Storch, I. 2002. On spatial resolution in habitat models: can small-scale forest structure explain capercaillie numbers? Conservation Ecology 6(1):6 [online] URL: http://www.consecol.org/vol6/iss1/art6.

Swistock, B. R., D. R. DeWalle, S. B. Horsley, R. P. Long, T. J. Hall, and S. Bailey. 1999. Pages 63-73 in W. E. Sharpe and J. R. Drohan, editors. The effects of acid deposition on Pennsylvania's forests. Environmental Resources Research Institute, Pennsylvania State University , University Park, Pennsylvania, USA.

Villard, M.-A. 2002. Habitat fragementation: major conservation issue or intellectual attractor? Ecological Applications 12(2):319-320.

Walters, C. J. 1986. Adaptive management of renewable resources. MacMillan, New York, New York, USA.

Walters, C. J., and C. S. Holling. 1990. Large-scale management experiments and learning by doing. Ecology 71:2060-2068.

Wiens, J. A. 1989. Spatial scaling in ecology. Functional Ecology 3:385-397.

Wolff, J. O., E. M. Schauber, and W. D. Edge. 1997. Effects of habitat loss and fragmentation on the behavior and demography of gray-tailed voles. Conservation Biology 11:945-956. 